\title{
Effect of Educational Program Based on Health Belief Model regarding Safe Childbirth on Selected Mode of Delivery among Primigravida
}

\section{Mervat Samy Amin', Hend Salah El-Din Mohamed Nasr ${ }^{2}$, Hend Abdallah Elsayed ${ }^{3}$ and Rehab Soliman Abdel-Aliem ${ }^{4}$}

(1) Nursing Educator at Secondary Technical Nursing School, Egypt, (2) Professor of Obstetrics and Gynecology Nursing, Faculty of Nursing, Zagzig University, Egypt and (3,4) Assistant Professor of Obstetrics and Woman's Health Nursing, Faculty of Nursing, Benha University, Egypt

\begin{abstract}
Background: Despite the advantages of natural childbirth and complications associated with cesarean section, rate of cesarean delivery had increased dramatically in recent years. Therefore, educational program is essential to reduce this trend. Aim of study: Was to evaluate the effect of educational program based on health belief model regarding safe childbirth on selected mode of delivery among primigravidae. Design: Quasi - experimental design was used to conduct this study. Setting: The study was conducted at out-patient clinic at Obstetrics and Gynecological department in Benha University Hospitals. Sample: A purposive sample of 300 women divided into two equal groups (study group $=150$ women who received educational program based on health belief model regarding safe child birth and control group $=150$ women who received routine hospital care. Tools: Three tools of data collection were used, a structured interviewing questionnaire, Champion's health belief model scale and women's choice mode of delivery sheet. Results: There was an increase in total mean score of five constructs of health belief model toward vaginal and cesarean delivery in study group compared to control group with highly statistically significant differences after educational program $(\mathrm{P} \leq 0.001)$. More than one third of study group pre educational program preferred vaginal delivery compared by more than half of study group post educational program. While less than two thirds of study group preferred cesarean delivery pre educational program compared by less than half post educational program. On the other hand, there were no statistically significant differences between control group pre and post educational program. Conclusion: The educational program based on health belief model had improved primigravidae's knowledge and health beliefs regarding mode of delivery and also improved the selection of vaginal delivery. Vaginal delivery was chosen more in study group after educational program compared by pre educational program. Recommendations: Health belief model could be used as a routine model in health care sitting to empower women with comprehensive information on the benefits and severity of the different modes of delivery.
\end{abstract}

Key words: Childbirth, Health Belief Model, Mode of Delivery

Introduction

Childbirth is one of the most challenging events in woman's life that considers important consequences from biological, mental, and social aspects. The process of childbirth occurs either by normal vaginal delivery or cesarean section, when childbirth naturally occurs, is called normal vaginal delivery whilst cesarean section is the delivery through abdominal wall or uterine incision (Aksoy et al., 2019). 
Primigravida women (vulnerable group for the study) is the one who is more anxious about labor because of lack of information and false beliefs about labor process, Thus Knowledge regarding the pregnancy and labor has a positive influence on primigravida, to take adequate care and intern leads to better compliance during labor process, there by leading to natural childbirth (Ratiyun et al., 2021).

Educational program is the most effective method that helps pregnant women especially primigravidae to overcome fears of natural delivery. Moreover, increasing women's awareness of benefits and disadvantages of childbirth type and the involvement in decision-making process of childbirth lead to a decrease in women's tendency to cesarean section delivery. The value of health educational programs depends on its effectiveness. The effectiveness of health educational programs to a large extent depends on the proper use of theories and models used in health education. The model used in this study is health belief model (Tavakoli, 2021).

Health Belief Model (HBM) is one of the most widely used conceptual framework for motivating people to take positive health actions that uses the desire to avoid a negative health consequence as the prime motivation. HBM is also a psychological precept that attempts to explain and predict health behaviors by focusing to predict a person's health behavior, including the use of health services and to justify intervention to alter maladaptive health behavior. The model consists of five constructs, including perceived susceptibility, perceived severity, perceived benefits, perceived barriers, cues to action (Sharama, 2019).
Nurses as midwives play an important role for promoting health. Traditionally, the focus of health promotion by nurses has been on disease prevention and correct miss concept and beliefs among women with respect to health. However, nursing role as promote of health is more complex, since nurses have multidisciplinary knowledge and experience of health promotion in nursing practice. Nurses play an important role in helping pregnant women to take active part in decision making process through providing adequate knowledge during pregnancy about safest mode of delivery following health belief model which help adaptation of health behavior (Thompson et al., 2020).

\section{Significance of the study}

Despite the benefits of normal vaginal delivery and complications associated with caesarean section, pregnant women commonly have a negative attitude toward this mode of childbirth due to the attribution of false complications. As such, rate of normal vaginal delivery has been reported to decline in recent years (Tofighi et al., 2017).

Caesarean section is often accompanied by many complications for both the mother and the fetus. Though caesarean section can be life saving for mother and fetus in certain situations, its excessive and unnecessary use is becoming a matter of concern due to increased request for CS without medical indications, maternal negative feelings toward vaginal delivery such as terror from labor pain and the baby's wellbeing concerns. Recently in Arab Republic of Egypt rate of elective Cesarean delivery was raised dramatically from $27.6 \%$ in 2010 to $52 \%$ in 2014and $65 \%$ in Gharbia in 2014. These rates are more than other rates quoted from diverse parts of the world, both 
in the developed and developing countries (Takegata et al., 2020).

Besides, the cesarean section rate at Benha University Hospital reached to 4626 cases in 2020 according to the last hospital register (Benha University Hospital Census, 2020). Designing and implementing educational program based on health belief model for changing primigravida's false beliefs about normal vaginal delivery as most primigravida prefer cesarean section although the potential complications on the mother and fetus. There is no study was done at obstetrics, gynecological department at Benha University addressed selected mode of delivery. So, the present study was conducted to evaluate the effect of educational program based on health belief model regarding safe childbirth on selected mode of delivery among primigravida.

\section{Aim of the study \\ The current study aimed to evaluate the effect of educational program based on health belief model regarding safe childbirth on selected mode of delivery among primigravidae.}

\section{Research Hypotheses}

- Primigravida who had received an educational program based on health belief model had improved knowledge and health beliefs regarding mode of delivery than who don't.

-There was difference between primigravida who had received educational program regarding selected mode of delivery than who don't.

\section{Subject and Methods}

\section{Research design:}

Quasi - experimental design was utilized to achieve the aim of the current study.

\section{Setting:}

The study was conducted in out-patient clinic at obstetrics and gynecological department in Benha University Hospitals

Sample type: A purposive sample.

Sample size: 300 primigravidae was selected according to inclusion and exclusion criteria and was equally divided into two groups (study group $=150$ women who received educational program based on health belief model regarding safe child birth and control group $=150$ women who received routine hospital care. Sample size was calculated utilizing following formula (Yamane, 1967).

$$
\mathrm{n}=\frac{\mathrm{N}}{1+\mathrm{N}(\mathrm{e}) 2}
$$

Where $\mathrm{n}=$ sample size $\mathrm{N}=$ total population number (1200) according to Benha University Hospital Census, 2018.e $=$ margin error (0.05).

\section{Inclusion criteria:}

-Primigravidae

- Single pregnancy, cephalic presentation

-Aged 20-35years old.

- In the $3^{\text {rd }}$ trimester.

-Educated women.

\section{Exclusion criteria:}

Have pregnancy-related complications such as (pregnancy-induced hypertension, gestational diabetes, fetal distress, cephalopelvic disproportion, cord prolapse, placenta abruption, placenta previa and overweight women).

\section{Tools for data collection:}

Three main tools were used for data collection:

\section{Tool I- Structured interviewing questionnaire}

This questionnaire was designed by the researcher after reviewing related literature (Hassani et al., 2018; Bahri et al.,2018; AlBattawi and Ibrahim,2017). It was written in an Arabic language in the form of closed 
and open ended questions and included three parts:

Part (1): Demographic characteristics such as (age, educational level, occupation, residence, monthly income and body measurements which include height, weight and body mass index) and obstetric history of the studied women such as (present gestational age, follow up care, time of starting follow up and number of visits each month).

Part (2): Factors affecting beliefs of primigravidae to choose mode of delivery. It included: baby's factors consisted of (5) items. Maternal factors consisted of (6) items. Social factors consisted of (5) items.

Part (3): Women's knowledge about mode of delivery, it composed of two sections:

Section (a): Women's knowledge about normal vaginal delivery, it included (3items).

Section (b): Women's knowledge about cesarean section, it included (4items).

\section{Scoring of knowledge:}

Each item was assigned a score of (3) given when the answer was completely correct, a score (2) was given when the answer was incompletely correct and a score (1) was given when the answer was don't known. The total score of each section was calculated by summation of the scores of its items. The total score for the knowledge of a participant was calculated by the addition of the total score of two sections ranged from (721). Women total knowledge score was classified as the following:

Poor knowledge when the total score less than $50 \%(7<10)$.

Average knowledge when the total score 50\% less than $75 \%(10<15)$.

Good knowledge when total score more than $75 \%(15-21)$.

\section{Tool II: The Champion's Health Belief Model Scale (CHBMS):}

Champion's Health Belief Model Scale was adopted from Champion, (1993) and adapted by the researcher then translated into Arabic language to assess women's health beliefs regarding mode of vaginal and cesarean delivery. It consisted of 5 constructs which included 20 items for each mode (normal vaginal delivery and cesarean section, perceived susceptibility (3 items), perceived benefits ( 8 items), perceived severity (3 items), perceived barriers (3 items), and cues to action (3 items).

\section{Scoring of health belief model:}

The items were judged according to three point likert scale continuum from disagree (1), uncertain (2) and agree (3), total score ranged from 20 to 60 for each five subscales, higher scores indicating extremely healthy beliefs but for concerning perceived barriers higher scores indicate more negative health beliefs.

Tool III: Women's choice of mode of delivery sheet.

This tool was developed by the researcher after reviewing the related literature (Loke et al., 2018, Tofighi et al., 2017), to determine women's decision regarding selecting the safest mode of delivery before and after the program. It included (2) items (preferred mode of delivery as normal vaginal delivery or cesarean section and reasons for preferred mode of delivery included (labor pain, the cost, doctor choice, health beliefs toward mode of delivery, the most common mode of delivery, having past knowledge about this mode of delivery and having knowledge from educational program).

\section{Tools validity and reliability:}

Tools of data collection were reviewed by panel expertise of three obstetrics nursing (1) professor of Obstetrics and Women Health Nursing Faculty of Nursing Ain Shams 
University, (1) professor of Obstetrics and Gynecology Nursing Faculty of Nursing Zagazig University, (1) professor of Obstetrics and Woman's Health Nursing Faculty of Nursing Benha University to test content validity. Modifications were done in the light of valuable comments such as modify some words to give the most appropriate meaning for the phrase which were not clear. Questionnaires were modified related to clarity of sentences, consistency, appropriateness of content, the sequence of items, accuracy, and relevance, comprehensiveness of tools. Reliability was done by Cronbach's alpha for test internal consistency for knowledge was equal 0.929 and for health belief model was equal 0.803 and for women's choice of mode of delivery was equal 0.756 .

\section{Ethical considerations:}

Ethical aspects were considered before implementation of the study as the following:

- The aim of the study was explained to each woman before applying the study.

- An oral consent was obtained from each woman to participate in the study.

- The study would not cause any physical, social or psychological risk on the participant.

- Maintain confidentiality, self- esteem and dignity of women.

- Withdraw from participation in the study at any time.

\section{Pilot study:}

The pilot study was carried out on ten percent of total sample (30 women) to test the clarity and applicability of the study tools as well as estimation of the time needed to fill the questionnaire. No required modifications were done. Women involved in the pilot were included in the main study sample.

\section{Field work:}

To fulfill the aim of the present study, the following phases were adopted, interviewing and assessment phase, planning phase, implementation and evaluation phase. These phases were carried out from the beginning of June 2019 and completed at the end of February 2020 covering nine months. The researcher visited the previously mentioned setting three days/weeks (Saturday, Monday, Tuesday) from $9.00 \mathrm{Am}$ to $12.00 \mathrm{pm}$.

\section{Interviewing and assessment phase:}

Interviewing and assessment phase was conducted in both groups. At the beginning of the interview the researcher greeted the women, introduced herself, explained the purpose of the study and provided the women with all information about the study (purpose, duration, and benefits) and took oral consent of participants in the study. Initial assessment (pretest) was done included assessment of the structured interview questionnaire, health belief model scale, women's choice mode of delivery. Tools were completed by the participants in both groups. The data obtained constituted the baseline for further comparison to evaluate the effect of educational program based on health belief model. The average time required for completion of this phase was around (20-30 minutes). The researcher interviewed about (2-3) women per day and totally (4-8) women per week to be prepared for the upcoming educational program sessions,

\section{Planning phase:}

Based on the results obtained from the pretest assessment of women's knowledge, health beliefs and choice mode of delivery. The researcher designed booklet about safe childbirth in simple Arabic language contained proper information about normal vaginal delivery such (definition, advantages, 
factors enhance normal vaginal delivery, symptoms and signs of normal vaginal delivery, complications and health instructions after delivery) and information about cesarean section such as(definition, advantages, indications for performing cesarean section, complications and health instructions after delivery). These information are supported by different illustrated pictures; the researcher used different teaching methods such as lecture, group discussion.

\section{Implementation phase:}

For the study group, each woman received four sessions: The duration of each session took approximately 30 minutes. The implementation phase took about four weeks' session. The researcher divided the women in the study group into 20 subgroups, each group consisted of 4-8 women per week. Each group attended 4 structured sessions for 30 minute per session. Women's telephone numbers were taken to ensure contact.

First session: The researcher distributed a guide line to each woman about safe child birth. Firstly, the researcher provided overview about the booklet, then took women's feedback about normal vaginal delivery, many women beliefs that normal vaginal delivery is a painful process, cause postpartum hemorrhage, cause injuries to mother and fetus during labor.

The researcher tried to change women's false beliefs about normal vaginal delivery through providing proper information regarding definition of normal vaginal delivery and benefits as it is a normal/ natural process, allow early breast feeding, faster recovery after delivery and became without pain due to advanced medical technology. The researcher supported the information with clear pictures. Then the researcher informed women with measures that can decrease the perception of pain, through relaxation techniques, breathing exercises, changing position, moving, walking and eating certain types of foods and fruits. At the end of the session, the researcher gave the women opportunity to express their opinion in the session, benefits acquired from the session and allow them to ask questions and answer to it.

Second session: In this session the researcher makes rapid revision on the previous session to ensure women contact for 5 minutes, then inform the women about how to overcome normal vaginal delivery complications such as perineal tears during labor, vaginal infection and perineal prolapse. The researcher clarifies that these complications can be avoided through avoiding pressure on the premium during labor, support the premium very well during labor, maintain proper hygienic measures during and after labor and following regular exercise as kegal exercise.

The researcher provided healthy instructions for women about how to get faster recovery after normal vaginal delivery such as maintaining adequate rest, taking healthy food and fresh fruits, walking, proper hygiene for the perineal area, avoid lifting heavy things, early breast feeding. At the end, the researcher gave the women five minutes to ask any question about complications and health instructions.

Third session: In this session, the researcher revised the previous sessions for providing feedback about previous sessions. Then, the researcher took women's feedback about cesarean delivery, most of women believed that cesarean delivery is the best mode of delivery, lower risk for fetal injuries during labor, lower pain than vaginal delivery. Some women perceived that cesarean delivery can cause abdominal wound infection, take long time for recovery.

The researcher provided the women with proper information about cesarean delivery 
such as definition, advantages, indications as it is an incision through abdominal wall to deliver baby, can save life of mother and fetus when vaginal delivery poses risks to the mother and the baby. this information supported by illustrated pictures. The researcher illustrated that cesarean delivery without urgent need isn't desired because complications of cesarean delivery outweigh its benefits.

Then the researcher informed women with measures that can decrease the perception that cesarean delivery causes abdominal wound infection and take long time for recovery through keeping wound cleaned and covered, daily shower, proper hand washing before dressing, proper nutrition, regular observation of wound, rest, walking and simple exercise and taking prescribed antibiotics.

Fourth session: In this session the researcher revised the previous sessions and gave the women opportunity to ask any question. The researcher illustrated complications that may be caused when performing cesarean delivery as infection during and after delivery, postpartum hemorrhage, thromboembolism and premature birth then provided health instructions to women about how to deal with cesarean wound with illustrated pictures. At the end of session, the researcher took women impression about both modes of delivery.

the control group, received the traditional prenatal care, the researcher started with control group and interviewed 2-3 women per day. There was no structured plan for the education. Otherwise, answered any women's questions about the educational topics as needed.

\section{Evaluation phase:}

Evaluation was done for study and control groups (posttest) after one month from implementation of the educational program. The researcher met the women to evaluate the effect of the educational program by using the same format of preprogram assessment tools (I, part 3, II, III) .

\section{Statistical analysis:}

Data was verified prior to computerized entry. The statistical package for social sciences (SPSS version 20) was used followed by data analysis and tabulation. Descriptive statistics were applied (e.g., mean, standard deviation, frequency and percentages). Also tests of significance (Chisquare test, fisher exact test and independent $t$ test) were applied to test the study hypothesis. Pearson correlation coefficients were used to investigate the relationship between study variables. A significant level value was considered when $\mathrm{p} \leq 0.05$. And A highly significant level value was considered when $\mathrm{p}<0.001$.

\section{Limitation of the study:}

Sometimes the sessions were protracted due to noise and other individual's interruption.

\section{Results:}

Table (1): Shows that, more than two thirds $70 \%$ and $68 \%$ of the study and control groups were in age group $20<25$ years old with mean \pm SD $24.68 \pm 3.51$ years and $24.68 \pm 3.25$ years respectively. Regarding educational level, less than half of the study and control groups $44 \%$ and $48 \%$ had university and secondary education. As regard occupation, more than half of study and control groups $59.3 \%$ and $62 \%$ were housewives respectively. Regarding the monthly income $76 \%$ and $70.7 \%$ of both groups had not enough. More than three quarters of both groups were living in urban areas respectively. 
Figure (1): Illustrates that, more than one third $37.3 \%$ and $34.7 \%$ of study and control groups had good total knowledge pre educational program. While, more than three quarters of study group $82.0 \%$ compared by more than one third $38.0 \%$ of control group had good total knowledge post educational program.

Table (2): Portrays that total mean score of constructs of health belief model toward vaginal delivery in study and control groups were $26.01 \pm 6.81$ and $26.78 \pm 6.76$ with no statistically significant difference $(p>0.05)$ pre educational program. Meanwhile post educational program, the total mean score of constructs of health belief model toward vaginal delivery in study group was increased compared to control group $46.76 \pm 5.21$ versus $26.90 \pm 6.75$ with highly statistically significant difference $(\mathrm{P} \leq 0.001)$.

Table (3): Reveals that total mean score of constructs of health belief model toward cesarean delivery in study and control groups were $25.24 \pm 6.10$ and $25.30 \pm 5.27$ with no statistically significant difference $(p>0.05)$ pre-educational program. Meanwhile post educational program, the total mean score of constructs of health belief model toward cesarean delivery in study group was increased compared to control group $51.40 \pm$ 4.58 versus $25.71 \pm 5.27$ with highly statistically significant difference $(\mathrm{P} \leq 0.001)$.

Table (4): Indicates that there was a significant positive correlation between total knowledge and health belief model between study and control groups regarding vaginal delivery pre educational program $(\mathrm{P} \leq 0.05)$. While there were a highly positive correlation in study group compared by control group post educational program $(\mathrm{P} \leq 0.001)$.

Table (5): Indicates that there were a highly significant positive correlation between total knowledge and health belief model between study and control groups regarding cesarean delivery pre and post educational program $(\mathrm{P} \leq 0.001)$.

Figure (2): Illustrates that less than two thirds $64.7 \%$ of study group preferred cesarean delivery pre educational program compared by less than half $40.7 \%$ post educational program. While more than half $62.7 \%$ of control group pre educational program compared by more than half $58.7 \%$ post educational program preferred cesarean delivery. Regarding vaginal delivery, more than one third $35.3 \%$ of study group pre educational program preferred vaginal delivery compared by more than half $59.3 \%$ of study group post educational program. In addition more than one third of control group $37.3 \%$ and $41.3 \%$ pre and post educational program preferred vaginal deliver 
Table (1): Distribution of women in study and control groups regarding demographic characteristics $(n=300)$.

\begin{tabular}{|c|c|c|c|c|c|c|}
\hline \multirow[t]{2}{*}{$\begin{array}{c}\text { Demographic } \\
\text { Characteristics }\end{array}$} & \multicolumn{2}{|c|}{$\begin{array}{l}\text { Study group } \\
(n=150)\end{array}$} & \multicolumn{2}{|c|}{$\begin{array}{c}\text { Control group } \\
(\mathbf{n}=\mathbf{1 5 0})\end{array}$} & \multirow[t]{2}{*}{$\overline{\mathrm{X}^{2} \backslash \mathrm{FET}}$} & \multirow[t]{2}{*}{$\overline{\text { p-value }}$} \\
\hline & No & $\%$ & No & $\%$ & & \\
\hline \multicolumn{7}{|l|}{ Age (years) } \\
\hline $20<25$ & 105 & 70.0 & 102 & 68.0 & \multirow{4}{*}{0.922} & \multirow{4}{*}{0.63} \\
\hline $25<30$ & 30 & 20.0 & 36 & 24.0 & & \\
\hline $30 \leq 35$ & 15 & 10.0 & 12 & 8.0 & & \\
\hline Mean \pm SD & \multicolumn{2}{|c|}{$24.68 \pm 3.51$} & \multicolumn{2}{|c|}{$24.68 \pm 3.25$} & & \\
\hline \multicolumn{7}{|l|}{ Educational level } \\
\hline Read and write & 15 & 10.0 & 12 & 8.0 & \multirow{4}{*}{$3.66^{\mathfrak{E}}$} & \multirow{4}{*}{0.300} \\
\hline Primary education & 9 & 6.0 & 3 & 2.0 & & \\
\hline Secondary education & 66 & 40.0 & 72 & 48.0 & & \\
\hline University education & 60 & 44.0 & 63 & 42.0 & & \\
\hline \multicolumn{7}{|l|}{ Occupation } \\
\hline Worked & 61 & 40.7 & 57 & 38.0 & \multirow[b]{2}{*}{0.22} & \multirow[b]{2}{*}{0.63} \\
\hline House wife & 89 & 59.3 & 93 & 62.0 & & \\
\hline \multicolumn{7}{|l|}{ Monthly income } \\
\hline Not enough & 114 & 76.0 & 106 & 70.7 & \multirow[b]{2}{*}{1.091} & \multirow[b]{2}{*}{0.296} \\
\hline Enough & 36 & 24.0 & 44 & 29.3 & & \\
\hline \multicolumn{7}{|l|}{ Residence } \\
\hline Urban & 117 & 78.0 & 120 & 80.0 & \multirow[b]{2}{*}{0.18} & \multirow[b]{2}{*}{0.67} \\
\hline Rural & 33 & 22.0 & 30 & 20.0 & & \\
\hline
\end{tabular}

${ }^{\mathrm{t}}$ FET: Fisher Exact Test 
Mervat Samy, Hend Salah El-Din Mohamed, Hend Abdallah and Rehab Soliman

Table (2): Mean score of total constructs of health belief model toward vaginal delivery in the study and control groups pre and post educational program $(\mathbf{n}=300)$.

\begin{tabular}{|c|c|c|c|c|c|c|c|c|c|}
\hline \multirow{3}{*}{ Constructs } & \multirow{3}{*}{$\begin{array}{l}\text { Maximu } \\
\text { m score }\end{array}$} & \multicolumn{2}{|c|}{ Pre- educational program } & \multirow{3}{*}{$\begin{array}{c}\text { Independent } \\
\text { t-test }\end{array}$} & \multirow[t]{3}{*}{ p-value } & \multicolumn{2}{|c|}{ Post educational program } & \multirow{3}{*}{$\begin{array}{c}\text { Independe } \\
\text { nt t-test }\end{array}$} & \multirow[t]{3}{*}{ p-value } \\
\hline & & $\begin{array}{l}\text { Study group } \\
\quad(n=150)\end{array}$ & $\begin{array}{c}\text { Control group } \\
\quad(n=150)\end{array}$ & & & $\begin{array}{l}\text { Study group } \\
\quad(n=150)\end{array}$ & $\begin{array}{c}\text { Control group } \\
\quad(n=150)\end{array}$ & & \\
\hline & & Mean \pm SD & Mean \pm SD & & & Mean \pm SD & Mean \pm SD & & \\
\hline $\begin{array}{l}\text { Perceived } \\
\text { susceptibility }\end{array}$ & 9 & $5.10 \pm 1.20$ & $5.20 \pm 1.11$ & 0.748 & 0.455 & $6.48 \pm 1.98$ & $5.25 \pm 1.10$ & 9.367 & $0.000 * *$ \\
\hline Perceived severity & 9 & $\begin{array}{c}4.49 \pm \\
1.66\end{array}$ & $4.68 \pm 1.53$ & 1.010 & 0.314 & $6.74 \pm 1.84$ & $4.84 \pm 1.53$ & 9.893 & $0.000 * *$ \\
\hline Perceived barriers & 9 & $3.87 \pm 2.02$ & $3.96 \pm 2.04$ & 0.369 & 0.712 & $7.08 \pm 1.57$ & $3.98 \pm 2.04$ & 8.911 & $0.000 * *$ \\
\hline Perceived benefits & 24 & $\begin{array}{c}10.67 \pm \\
4.49\end{array}$ & $10.06 \pm 4.50$ & 0.744 & 0.457 & $\begin{array}{c}21.22 \pm \\
3.43\end{array}$ & $11.06 \pm 4.50$ & 4.671 & $0.000 * *$ \\
\hline Cues to action & 9 & $\begin{array}{c}4.87 \pm \\
2.49\end{array}$ & $4.88 \pm 2.53$ & 0.023 & 0.982 & $\begin{array}{c}6.24 \pm \\
2.05\end{array}$ & $4.98 \pm 2.53$ & 1.352 & $0.017 *$ \\
\hline Total & 60 & $26.01 \pm 6.81$ & $26.78 \pm 6.76$ & 0.978 & 0.329 & $\begin{array}{c}46.76 \pm \\
5.21\end{array}$ & $26.90 \pm 6.75$ & 4.363 & $0.000 * *$ \\
\hline
\end{tabular}


Table (3): Mean score of total constructs of health belief model toward cesarean delivery in the study and control groups pre and post educational program $(n=300)$.

\begin{tabular}{|c|c|c|c|c|c|c|c|c|c|}
\hline \multirow{3}{*}{ Constructs } & \multirow{3}{*}{$\begin{array}{l}\text { Maximum } \\
\text { score }\end{array}$} & \multicolumn{2}{|c|}{ Pre- educational program } & \multirow{3}{*}{$\begin{array}{c}\text { Independent } \\
\text { t test }\end{array}$} & \multirow{3}{*}{$\begin{array}{c}p- \\
\text { value }\end{array}$} & \multicolumn{2}{|c|}{ Post educational program } & \multirow{3}{*}{$\begin{array}{c}\text { Independent } \\
\text { t test }\end{array}$} & \multirow[t]{3}{*}{ p-value } \\
\hline & & $\begin{array}{l}\text { Study group } \\
\quad(n=150)\end{array}$ & $\begin{array}{c}\text { Control } \\
\text { group } \\
(n=150)\end{array}$ & & & $\begin{array}{c}\text { Study group } \\
(\mathbf{n}=150)\end{array}$ & $\begin{array}{c}\text { Control group } \\
(n=150)\end{array}$ & & \\
\hline & & Mean \pm SD & Mean \pm SD & & & Mean \pm SD & Mean \pm SD & & \\
\hline $\begin{array}{l}\text { Perceived } \\
\text { susceptibility }\end{array}$ & 9 & $5.04 \pm 1.79$ & $5.20 \pm 1.72$ & 0.755 & 0.451 & $\begin{array}{c}7.26 \pm \\
1.82\end{array}$ & $5.21 \pm 1.72$ & 0.292 & $\begin{array}{c}0.000^{*} \\
*\end{array}$ \\
\hline Perceived severity & 9 & $4.51 \pm 2.09$ & $4.62 \pm 2.13$ & 0.437 & 0.663 & $7.16 \pm 2.04$ & $4.26 \pm 2.13$ & 2.236 & $\begin{array}{c}0.000 * \\
*\end{array}$ \\
\hline Perceived barriers & 9 & $3.83 \pm 1.63$ & $3.12 \pm 1.29$ & 1.683 & 0.094 & $8.6 \pm .96$ & $3.25 \pm 1.29$ & 3.799 & $\begin{array}{c}0.000 * \\
*\end{array}$ \\
\hline Perceived benefits & 24 & $10.39 \pm 3.56$ & $10.74 \pm 3.43$ & 0.858 & 0.392 & $\begin{array}{c}20.82 \pm \\
3.98\end{array}$ & $10.99 \pm 3.43$ & 0.186 & $\begin{array}{c}0.000 * \\
*\end{array}$ \\
\hline Cues to action & 9 & $3.46 \pm 2.15$ & $3.62 \pm 2.14$ & 0.645 & 0.520 & $\begin{array}{c}7.54 \pm \\
2.03\end{array}$ & $3.72 \pm 2.14$ & 3.811 & $\begin{array}{c}0.000 * \\
*\end{array}$ \\
\hline Total & 60 & $25.24 \pm 6.10$ & $\begin{array}{c}25.30 \pm \\
5.27\end{array}$ & 1.598 & 0.111 & $\begin{array}{l}51.40 \quad \pm \\
4.58\end{array}$ & $25.71 \pm 5.27$ & 3.680 & $\begin{array}{c}0.000^{*} \\
*\end{array}$ \\
\hline
\end{tabular}

* statistically significant difference $(\mathrm{P} \leq 0.05)$.

** Highly statistically significant difference $(\mathrm{P} \leq 0.001)$. 
Table (4): Correlation between total knowledge and total health belief model between study and control groups regarding vaginal delivery pre and post educational program(n=300).

\begin{tabular}{|c|c|c|c|c|c|c|c|c|}
\hline \multirow{5}{*}{$\begin{array}{c}\text { Total } \\
\text { knowledge } \\
\text { about vaginal } \\
\text { delivery }\end{array}$} & \multicolumn{4}{|c|}{ Pre- educational program } & \multicolumn{4}{|c|}{ Post educational program } \\
\hline & \multirow{2}{*}{\multicolumn{2}{|c|}{$\begin{array}{l}\text { Study group } \\
(\mathrm{n}=150)\end{array}$}} & \multirow{2}{*}{\multicolumn{2}{|c|}{$\begin{array}{l}\text { Control group } \\
(\mathrm{n}=150)\end{array}$}} & \multirow{2}{*}{\multicolumn{2}{|c|}{$\begin{array}{l}\begin{array}{l}\text { Study group } \\
(n=150)\end{array} \\
\text { Health beliefs }\end{array}$}} & \multirow{2}{*}{\multicolumn{2}{|c|}{$\begin{array}{c}\begin{array}{c}\text { Control group } \\
(n=150)\end{array} \\
\text { Health beliefs }\end{array}$}} \\
\hline & & & & & & & & \\
\hline & $\mathrm{r}$ & p-value & $\mathrm{r}$ & p-value & $\mathrm{r}$ & p-value & $\mathrm{r}$ & p-value \\
\hline & 0.164 & $0.045^{*}$ & 0.224 & $0.006^{*}$ & 0.758 & $0.000 * *$ & 0.236 & $0.004 *$ \\
\hline
\end{tabular}

Table (5): Correlation between total knowledge and total health belief model between study and control groups regarding cesarean delivery pre and post educational program $(n=300)$.

\begin{tabular}{|c|c|c|c|c|c|c|c|c|}
\hline \multirow{5}{*}{$\begin{array}{c}\text { Total } \\
\text { knowledge } \\
\text { about } \\
\text { cesarean } \\
\text { delivery }\end{array}$} & \multicolumn{4}{|c|}{ Pre- educational program } & \multicolumn{4}{|c|}{ Post educational program } \\
\hline & \multirow{2}{*}{\multicolumn{2}{|c|}{ 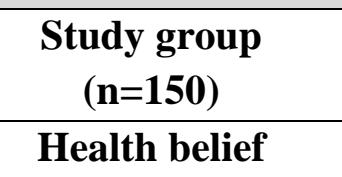 }} & \multirow{2}{*}{\multicolumn{2}{|c|}{$\begin{array}{c}\text { Control group } \\
(\mathbf{n}=\mathbf{1 5 0})\end{array}$}} & \multirow{2}{*}{\multicolumn{2}{|c|}{ 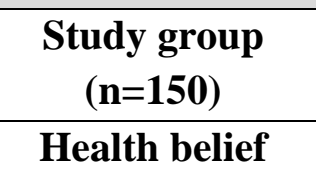 }} & \multirow{2}{*}{\multicolumn{2}{|c|}{$\begin{array}{c}\begin{array}{c}\text { Control group } \\
(\mathrm{n}=150)\end{array} \\
\text { Health belief }\end{array}$}} \\
\hline & & & & & & & & \\
\hline & $\mathrm{r}$ & p-value & $\mathrm{r}$ & $\mathrm{p}$-value & $\mathrm{r}$ & p-value & $\mathrm{r}$ & $\mathrm{p}$-value \\
\hline & 0.707 & $0.000 * *$ & 0.727 & $0.000 * *$ & 0.831 & $0.000 * *$ & 0.756 & $0.000 * *$ \\
\hline
\end{tabular}

** highly statistically significant difference $(\mathrm{P} \leq 0.001)$

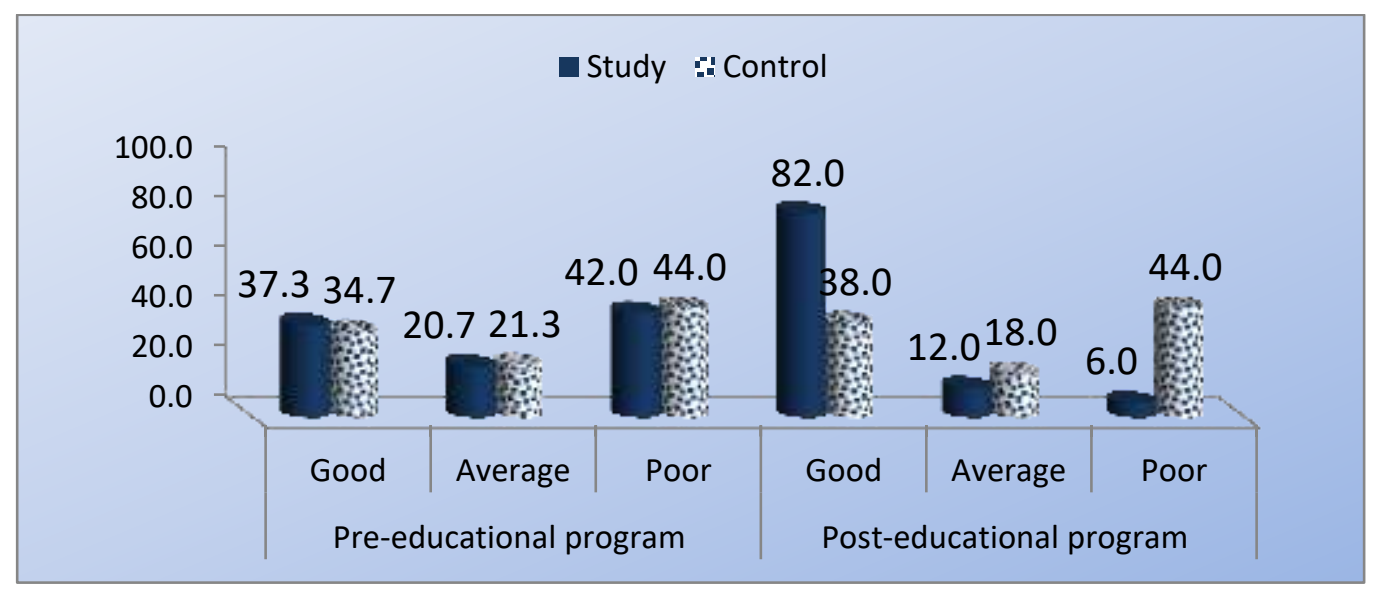

Figure (1): Distribution of women in the study and control groups regarding total knowledge scores pre and post educational program based on health belief model $(n=300)$. 


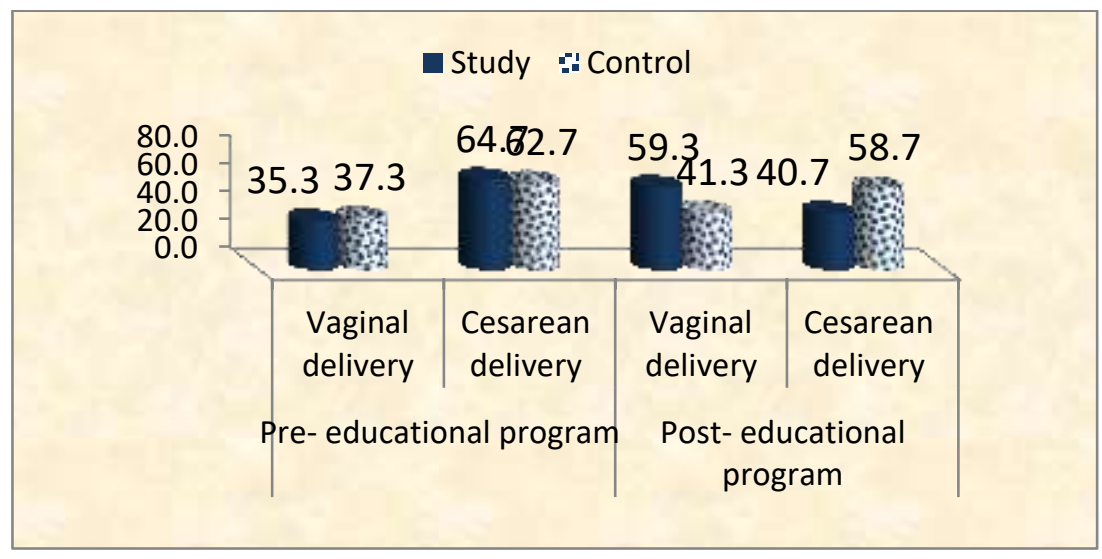

Figure (2): Distribution of women in the study and control groups regarding choice of mode of delivery pre and post educational program based on health belief model $(n=300)$.

\section{Discussion}

\section{Regarding}

demographic characteristics: The result of current study showed that, more than two thirds of the study and control groups were in age group $20<25$ years old with mean \pm SD $24.68 \pm 3.51$ years and $24.68 \pm 3.25$ years respectively. Regarding educational level, less than half of the study and control groups had university and secondary education. As regard occupation, more than half of study and control groups were housewives respectively. Regarding the monthly income, more than three quarters in study group and more than two thirds in control group had not enough. More than three quarters of both groups were living in urban areas respectively.

These findings were in the same line with Ghasemi et al., (2017) study which entitled, the impact of educational intervention based on health belief model in choosing delivery mode in primigravidae pregnant women and reported that the mean age of the pregnant women in the intervention group was $24.52 \pm 3.57$, and it was $24.19 \pm 3.18$ in the control group. Also reported that $44.5 \%$ of the intervention group had university education compared by $48.8 \%$ of the control group had secondary education. In term of occupation, most of the pregnant women were housewife in the intervention group $60.9 \%$ compared by $69.1 \%$ in the control group. With regards to monthly income, most of the pregnant women income had not enough in both the intervention and the control groups $76.1 \%$ and $72.1 \%$. According residence $75 \%$ in intervention group and $80 \%$ in control group were living in urban areas. While, these findings were in contrast with Masoumi et al., (2018) study entitled, effect of training preparation for childbirth on fear of normal vaginal delivery and choosing the type of delivery among pregnant women in Hamadan, Iran and found that the mean age of women in study group was $32.9 \pm 7.9$ (rang from 25 to 30 years) and in control group was $32.9 \pm 7.9$ (rang from 25 to 30 years). From the researcher point of view, the homogeneity of the women in the term of age were due to all participants were primigravidea and this is the age of marriage in Egypt. Also most of the studied women were housewives as a result of increasing unemployment level among women and most men preferred the wives being not worked in Egypt.

Regarding mean score of total constructs of health belief model toward vaginal delivery in the study and control groups pre and post educational program. The current 
study portrayed that total mean score of constructs of health belief model toward vaginal delivery in study and control groups had no statistically significant difference pre educational program. Meanwhile post educational program, the total mean score of constructs of health belief model toward vaginal delivery in study group was increased compared to control group with highly statistically significant difference. These findings were in accordance with Bahri et al., (2020) study entitled, application of the health belief model educational program to reduce the tendency of cesarean birth and found that there was no significant difference between the two groups regarding total constructs of the HBM before intervention $(p>0.05)$, but the results showed a significant difference between the two groups after 1-month intervention ( $\mathrm{p}<$ $.0001)$.

Regarding mean score of total constructs of health belief model toward cesarean delivery in the study and control groups pre and post educational program. The current study revealed that total mean score of constructs of health belief model toward cesarean delivery in study and control groups had no statistically significant difference pre educational program. Meanwhile post educational program, the total mean score of constructs of health belief model toward cesarean delivery in study group was increased compared to control group with highly statistically significant difference. These findings were in accordance with Darwish et al., (2019) who found that there was no significant difference between the two groups regarding total constructs of the HBM before intervention $(p>0.05)$, but the results showed the total mean score of constructs of health belief model toward cesarean delivery in study group was increased compared to control group with a significant difference between the two groups $(\mathrm{p}<.0001)$. This may be due to effectiveness of educational program administered based on health belief model.

Regarding correlation between total knowledge and total health belief model of both modes of delivery. The current study indicated that there was a significant positive correlation between total knowledge and health belief model between study and control groups regarding vaginal delivery pre educational program. While there was a highly positive correlation in study group compared by control group post educational program .These findings were in same line with Safari-Moradabadi et al., (2018) study entitled, investigating the delivery type among primiparous women in Bandar Abbas according to the health belief model and found that a significant positive correlation was observed between the total constructs of the model and the total knowledge of the two groups pre and post educational program. This may be due to effectiveness of educational program administered based on health belief model.

Regarding correlation between total knowledge and total health belief model about cesarean delivery. The current study indicated that there were a highly significant positive correlation between total knowledge and health belief model between study and control groups regarding cesarean delivery pre and post educational program.These findings were agreed with Baghiani et al., (2017) study entitled, the effect of educational intervention on selection of delivery method based on health belief model and reported that there was a significant positive correlation between total knowledge and total health belief model between case and control groups regarding cesarean section after intervention.

Regarding total knowledge scores, the current study illustrated that, more than one third of study and control groups had good total knowledge pre educational program. While more than three quarters of study group 
compared to more than one third of control group had good total knowledge post educational program.

These findings were in the same line with Ahmed and Khairi, (2019) study entitled, effectiveness of childbirth classes regarding labor's Knowledge and practices on primigravidae pregnant women and showed that both study and control groups had good knowledge on childbirth before program 39\% and $34 \%$ and after the program more than three quarters of study group compared to more than one third of control group had good knowledge on child birth $79 \%$ and $35 \%$. This result may be due to the effectiveness of the educational program on improving knowledge about mode of delivery among primigravidae women.

Regarding choice of mode of delivery pre and post educational program based on health belief model. The current study illustrated less than two thirds of study group preferred cesarean delivery pre educational program compared by less than half post educational program. While more than half of control group pre educational program compared by more than half post educational program preferred cesarean delivery. Regarding vaginal delivery, more than one third of study group pre educational program preferred vaginal delivery compared by more than half of study group post educational program. In addition, more than one third of control group pre and post educational program preferred vaginal delivery.

These findings were supported with Andaroon et al., (2020) study entitled, the effect of individual counseling on attitudes and decisional conflict in the choice of delivery among nulliparous women. The result showed before the intervention, there was no significant difference between the two groups in terms of preferred delivery $(\mathrm{P}=0.058)$. However, the results showed that after the intervention, there were significant differences between the two groups in terms of preferred delivery $(\mathrm{P}<$ 0.001 ) and the results showed that $61.1 \%$ of those in intervention group had chosen natural childbirth and $41.4 \%$ of those in the control group had chosen natural childbirth. Furthermore, $48.9 \%$ of those in intervention group had chosen cesarean section, while $55.6 \%$ of those in the control group had chosen cesarean section.

These were in the same line with Hassani et al., (2018) who found that before conducting the instructional intervention, both groups had intended to select CS. After the intervention, in the treatment group $60 \%$ mentioned natural delivery as their final choice.

\section{Conclusion}

The educational program based on health belief model was effective in improving total knowledge score and total health belief model score regarding both modes of delivery in study group than control group. There were highly statistically differences between study and control groups regarding total five constructs of health belief model regarding vaginal delivery and cesarean delivery after educational program. In addition, there were highly positive correlation between total knowledge and health belief model regarding vaginal delivery in study group compared by control group post educational program. Also there were a highly significant positive correlation between total knowledge and total health belief model among studied women (study and control group) regarding cesarean delivery pre and post educational program. Moreover, vaginal delivery was chosen more in study group after educational program. While choice of cesarean delivery was lower after educational program. Therefore, the study aim was achieved and the study hypotheses were supported. 


\section{Recommendations:}

1-Health belief model could be used as a routine model in health care sitting to empower women with comprehensive information on the benefits and severity of the different modes of delivery.

2- A simplified and comprehensive booklet about safe childbirth should be available for pregnant women to help them select the safest mode of delivery suitable for women's health.

\section{Further studies}

1- Replicate this study using larger samples of the population and include more than one hospital with different affiliations in different regions of Egypt in order to generalize the findings.

2-Giving educational program for nurses about using health belief model in the routine care of pregnant women that help in changing false beliefs.

\section{References}

Ahmed, H. and Khairi, A. (2019). Effectiveness of Childbirth Classes Regarding Labor Knowledge and Practices on Primigravida Woman in Al-Elwiya Maternity Teaching Hospital, Kufa Journal for Nursing sciences, 9(2):1-9.

Aksoy, M., Aksoy, A., Dostbil, A., Celik, M. and Ince, I. (2019). The relationship Between Fear of Childbirth and Women's Knowledge about Bain less Childbirth, Obstetrics and gynecology International Journal, Turkey, 3 (82): 201-208.

Al-Battawi, J. and Ibrahim, W. (2017). Applying Health Belief Model to Predict Factors Influencing Women Decision Regarding Mode of Delivery, Journal of Nursing and Health Science, Egypt, 6 (6): 4456.

Andaroon, N., Kordi, M., Kimiaee, S. A. and Esmaeili, H. (2020). The Effect of Individual Counseling on Attitudes and Decisional
Conflict in The Choice of Delivery among Nulliparous Women, Journal of Education and Health Promotion, 9 (4): 35- 42.

Baghiani, M., Hashemifard, T., Jafari, S., Yadollahi, P., Kamali, M. and Hashemifard, F. (2017). The effect of Educational Intervention on Selection of Delivery Method Based on Health Belief Model, Journal of Community Health Research, 3(2):115-123.

Bahri, N., Hesar, F. and Bahri, N. (2020). Application of the Health Belief Model Educational Program to Reduce the Tendency of Cesarean Birth, International Journal of Childbirth, 5(3): 200-208.

Bahri, N., Rahmani, R., Moshki, M., Banafshe, E. and Amiridelui, M. (2018). Effectiveness of an Educational Program Based on Health Belief Model Regarding Safe Childbirth on Selected Delivery Mode Among Pregnant Women, Quarterly of Horizon of Medical Sciences, Iran, 24 (4): 255-262.

Champion, VL. (1993). Instrument refinement for breast cancer screening behaviors. Nurs Res; 42 (3):139-143.

Darwish, D., Fiala, L., and Refaat, A. (2019). Factors Influencing the Decision-making Process Regarding Mode of Delivery Among Women Attending Primary Health Care Units in Ismailia District, International Journal of Advanced Community Medicine, 2(2): 34-42.

Ghasemi1,S., Nazari1,M. ,Vafaeiz,H. and Fararouei, M.(2017). The Impact of Educational Intervention Based on health belief model in Choosing Delivery Mode in Primigravida Pregnant Women, International Journal of Women's Health and Reproductive Science, Iran, 5(1): 47-54.

Hassani, L., Aghamolaei, T., Ghanbarnejad, A. and Dadipoor, S. (2018). The Effect of an instructional Program Based on Health Belief 
Model in Decreasing Cesarean Rate Among Primiparous Pregnant Mothers, Journal of Education and Health promotion, Iran, 5 (4), 115.

Loke, A., Davies, L. and Li, S. (2018). Factors Influencing the Decision That Women Make on Their Mode of Delivery: The Health Belief Model, British Maternal Care, health services research, USA,15(1): 274-288.

Masoumi, S., Kazemi, F., Oshvandi, K., Jalali, M., Esmaeili-Vardanjani, A. and Rafiei, H. (2018). Effect of Training Preparation for Childbirth on Fear of Normal Vaginal Delivery and Choosing The type of Delivery among Pregnant Women in Hamadan, Iran: a randomized controlled trial, Journal of Family and Reproductive Health, 10(3): 115135.

Ratiyun, R., Pawiliyah, P., Rahmawati, I. and Hilda, H. (2021). The Relation Between Knoweldge of Pregnant Women in The Third Trimester with The Level of Anxiety in Dealing with Childbirth in The Working Area of Puskesmas Pasar Ikan Bengkulu City, Al Insyirah International Scientific Conference on Health, 2(3): 378-391.

Safari-Moradabadi, A., Mehraban, M., Alavi, A., Pormehr-Yabandeh, A., Ghiaspour, T. and Dadipoor, S. (2018). Investigating The Delivery Type Among Primiparous Women in Bandar Abbas According to The Health Belief Model, World Family Medicine, 16 (1): 121-126.

Sharama, M. (2019). Therioritical Foundations of Health Education and Health Promotion.3rd ed, Jones and Bartlett publishers learning, LLC, An Ascend learning company, USA, p.60.

Takegata, M., Smith, C., Nguyen, H., Thi, H., Thi Minh, T., Day, L. and Yoshida, L. (2020). Reasons for Increased Caesarean
Section Rate in Vietnam: A qualitative Study Among Vietnamese Mothers and Health Care Professionals, Healthcare Multidisciplinary Digital Publishing Institute, 8(1): 41-53.

Tavakoli, H. (2021). The Impact of an Educational Intervention Based on Theory of Planned Behavior on Selecting Mode of Delivery in Primigravidae Women with Intention of Elective Cesarean Section, Journal of Midwifery and Reproductive Health, Iran, 9(2): 2753-2761.

Thompson, D., Leach, M., Smith, C., Fereday, J.and May, E. (2020). How Nurses and Other Health Professionals Use Learning Principles in Parent Education Practice: A scoping review of the literature, Heliyon, 6 (3): 34-86.

Tofighi,M., Behmanesh,F., Mashmuli,F.and Azimi, H. (2017).The Effect of Prenatal Group Education on Knowledge, Attitude and Selection of Delivery Type in Primiparous Women, Journal of Medical Education, Iran,10 (2):124-130.

Yamane, T. (1967). Statistics, an Introductory Analysis, $2^{\text {nd }}$ ed., New York: Harper and Row. 
تأثير برنامج تعليمي قائم على نموذج المعتق الصحي فيما يتعلق باختيار طريقة الولادة الآمنة بين البكريات مرفت سامي امين- هند صلاح الدين محم نصر - هند عبد الله السيد عفيفي- رحاب سليمان عبد العليم

على الرغم من مزايا الو لادة الطبيعية والمضاعفات المرتبطة بالو لادة القيصرية ، فقد زاد معدل الولادة

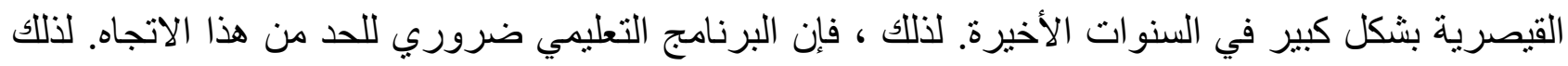

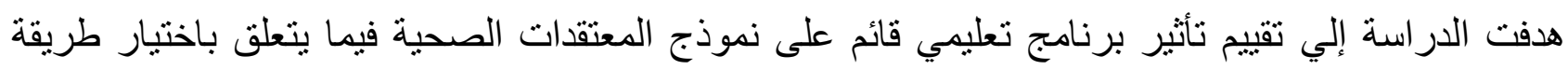

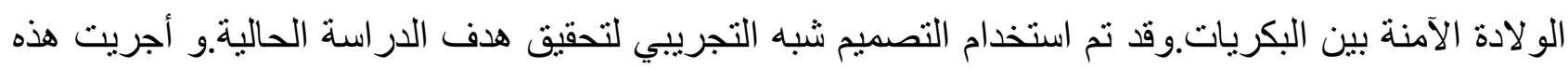

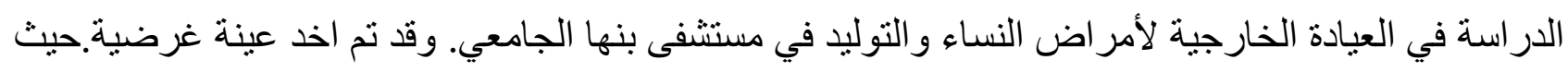

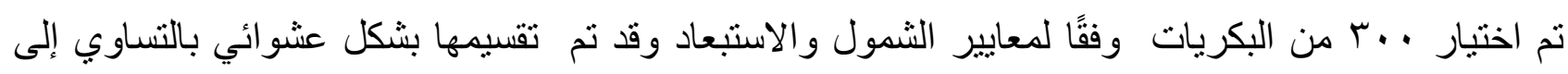

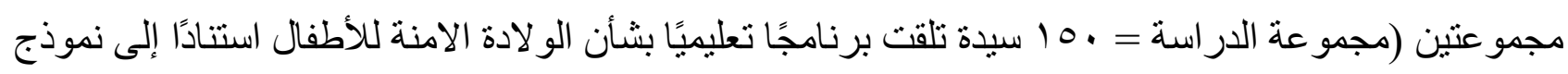

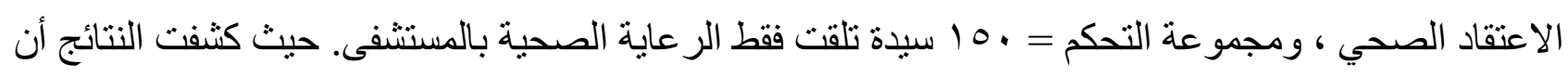
هناك تحسن في مجموع درجات المعرفة في مجمو عة الدراسة مقارنة بمجموعة التحكم. كانت هناك زئل زيادة في

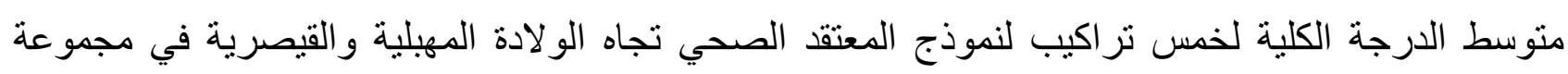

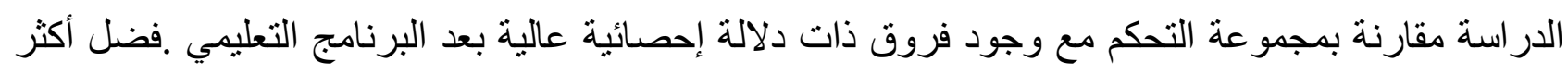

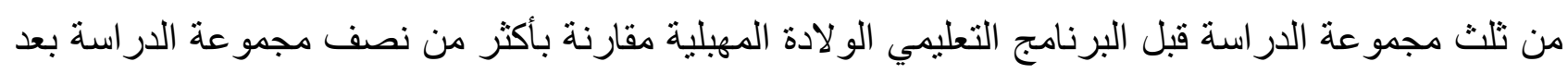

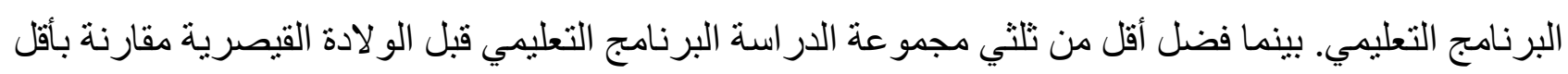

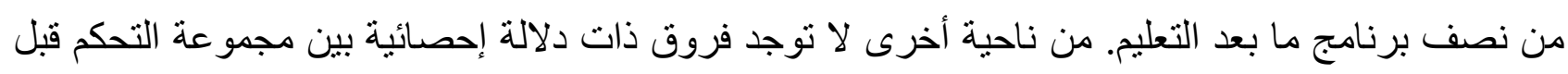

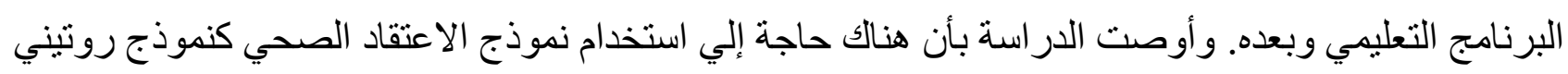

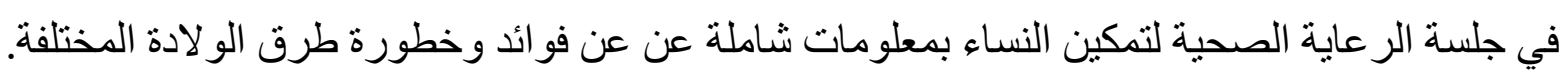

